\title{
Using metformin in the presence of renal disease
}

\author{
Current guidelines are too restrictive, and many patients who could benefit are missing out
}

\author{
Tahseen A Chowdhury consultant in diabetes, Roisin Wright lead diabetes nurse, M Magdi Yaqoob \\ professor in clinical nephrology
}

Departments of Diabetes and Nephrology, Barts and the London School of Medicine and Dentistry, London E1 1BB, UK.

In January, the electronic Medicines Compendium (eMC) updated the Summary of Product Characteristics for Glucophage (metformin), approved by the UK Medicines and Healthcare Products Regulatory Agency (MHRA). The summary states that "Metformin may be used in patients with moderate renal impairment, stage $3 \mathrm{a}$ (creatinine clearance $[\mathrm{CrCl}] 45-59 \mathrm{~mL} / \mathrm{min}$ or estimated glomerular filtration rate [eGFR] 45-59 $\mathrm{mL} / \mathrm{min} / 1.73 \mathrm{~m}^{2}$ ) only in the absence of other conditions that may increase the risk of lactic acidosis ... If $\mathrm{CrCl}$ or eGFR fall $<45 \mathrm{~mL} / \mathrm{min}$ or $<45 \mathrm{~mL} / \mathrm{min} / 1.73 \mathrm{~m}^{2}$ respectively, metformin must be discontinued immediately." This is reiterated in the patient information leaflet.

Interestingly, the summary for generic metformin states that "Renal failure or renal dysfunction (creatinine clearance $<60$ $\mathrm{ml} / \mathrm{min}$ )" is a contraindication to use. In the face of burgeoning levels of type 2 diabetes and associated renal disease, we believe that this restriction is too conservative and will deny an important drug to many thousands of people with diabetes who are likely to benefit from its important clinical effects and have few alternative treatments.

Metformin is recommended as the first line oral hypoglycaemic drug for patients with type 2 diabetes in national and international guidelines. ${ }^{23}$ The drug is the only one of many diabetes drugs to show cardiovascular benefits, especially in overweight or obese patients with type 2 diabetes. ${ }^{4}$ Metformin is also useful in overweight patients with type 1 diabetes, ${ }^{5}$ women with gestational diabetes or polycystic ovary syndrome, ${ }^{6}$ and in people at high risk of developing diabetes. ${ }^{7}$ There is some epidemiological evidence that metformin may reduce the risk of cancer in people with type 2 diabetes. ${ }^{8}$ The drug has been safely and widely prescribed for over 50 years and benefited millions of people. The adverse gastrointestinal effects of metformin are usually mild and temporary, and the drug does not induce weight gain. Use of metformin with insulin is both insulin dose sparing and weight sparing.

\section{Risk of lactic acidosis overstated}

Around a quarter of all patients with type 2 diabetes develop diabetic nephropathy, and the condition is the commonest cause of end stage renal failure in most developed countries. The concerns over metformin and renal impairment arise from the perceived risk of lactic acidosis in such patients. Although metformin overdose may be linked with lactic acidosis, a recent systematic review of cases reporting a link between metformin and lactic acidosis suggests no direct causal link and that other factors (such as sepsis or hepatic or cardiac failure) may be implicated. ${ }^{9}$ Indeed, a Cochrane review on the subject concluded that there is no evidence from prospective or observational studies that metformin is associated with lactic acidosis, nor even associated with raised lactate concentrations..$^{10}$ This is supported by a review of the General Practice Research Database, which showed a crude rate of lactic acidosis of 3.3 per 100000 patient years among people taking metformin, compared with 4.8 per 100000 patient years among those taking sulfonylurea. ${ }^{11}$

Nevertheless, the relatively unfounded concerns mean that large numbers of patients with type 2 diabetes are not receiving metformin, and indeed this number could grow if pharmaceutical guidelines are adhered to. A recent survey in the US suggests that if all patients with diabetes and eGFR $>30 \mathrm{~mL} / \mathrm{min} / 1.73$ $\mathrm{m}^{2}$ were prescribed metformin, roughly one million more people would be taking the drug. ${ }^{12}$

\section{Wider use}

Premature cessation of metformin in patients with renal disease may expose them to considerable harm. In clinical practice, we often see premature cessation of metformin leading to poor glucose control, and further deterioration in renal function. Diabetic patients with renal disease have a higher cardiovascular risk, and denying them metformin may increase this risk. Although several new drugs are available for use in people with type 2 diabetes, most are contraindicated or not licensed for use in renal impairment. Glitazones are associated with weight gain, fluid retention, heart failure, and possibly postmenopausal fractures. Saxagliptin is associated with heart failure, and sulfonylureas and insulin are associated with hypoglycaemia and weight gain - adverse effects that are particularly concerning in patients with renal disease. 
Guidelines from the UK National Institute for Health and Clinical Excellence (NICE) suggest that metformin dose should be reviewed at an eGFR of 45 and stopped at an eGFR of $30 .^{2}$ There is accumulating evidence, however, to suggest an important pharmacogenetic component to metformin metabolism, and this may enable some patients to continue the drug at lower levels of renal function. ${ }^{13}$ Dosing may be guided by wider use of plasma metformin concentrations in such patients, although further research evidence is required before this practice can be advocated. Nevertheless, NICE guidelines are pragmatic and can safely be used in clinical practice. We would encourage clinicians to use these guidelines and reassure patients that metformin is perfectly safe in stable renal disease. Patients should, however, be advised to stop metformin during periods of acute illness (such as gastrointestinal upset or other infections), where renal function may acutely deteriorate, and restart metformin when they have recovered.

Competing interests: We have read and understood BMJ policy on declaration of interests and declare that we have no competing interests. Provenance and peer review: Not commissioned; externally peer reviewed.

1 Glucophage $500 \mathrm{mg}$ and $850 \mathrm{mg}$ film coated tablets. 2015. www.medicines.org.uk/emc/ medicine/1043.
2 NICE. Type 2 diabetes: the management of type 2 diabetes. NICE guideline CG87. 2009. www.nice.org.uk/guidance/cg87/chapter/guidance.

3 Inzucchi SE, Bergenstal RM, Buse JB, et al. Management of hyperglycemia in type 2 diabetes: a patient-centered approach. Position statement of the American Diabetes Association (ADA) and the European Association for the Study of Diabetes (EASD). Diabetes Care 2012;35:1364-79.

4 Holman RR, Paul SK, Bethel MA, Matthews DR, Neil HAW. 10-year follow-up of intensive glucose control in type 2 diabetes. N Engl J Med 2008;359:1577-89.

5 Moon RJ, Bascombe LA, Holt RI. The addition of metformin in type 1 diabetes improves insulin sensitivity, diabetic control, body composition and patient well-being. Diabetes Obes Metab 2007;9:143-5.

6 Lautatzis ME, Goulis DG, Vrontakis M. Efficacy and safety of metformin during pregnancy in women with gestational diabetes mellitus or polycystic ovary syndrome: a systematic review. Metabolism 2013:62:1522-34.

7 Knowler WC, Barrett-Connor PH, Fowler SE, et al. Reduction in the incidence of type 2 diabetes with lifestyle intervention or metformin. N Engl J Med 2002;346:393-403.

8 Landman GW, Kleefstra N, van Hateren KJ, Groenier KH, Gans RO, Bilo HJ. Metformin associated with lower cancer mortality in type 2 diabetes: ZODIAC-16. Diabetes Care 2010;33:322-6.

9 Inzucchi SE, Lipska KJ, Mayo H, Bailey CJ, McGuire DK. Metformin in patients with type 2 diabetes and kidney disease: : a systematic review. JAMA 2014;312:2668-75.

10 Salpeter SR, Greyber E, Pasternak GA, Salpeter EE. Risk of fatal and nonfatal lactic acidosis with metformin use in type 2 diabetes. Cochrane Database Syst Rev 2010;4:CD002967.

11 Bodmer M, Meier C, Krahanbuhl S, Jick SS, Meier CR. Metformin, sulphonylureas or other antidiabetic drugs and the risk of lactic acidosis or hypoglycaemia. Diabetes Care 2008:31:2086-91.

12 Flory $\mathrm{JH}$, Hennessy S. Metformin use reduction in mild to moderate renal impairment: possible inappropriate curbing of use based on Food and Drug Administration contraindications. JAMA Intern Med 2015;175:458-9.

13 Shu Y, Sheardown SA, Brown C, et al. Effect of genetic variation in the organic cation transporter 1 (OCT1) on metformin action. J Clin Invest 2007;117:1422-31.

Cite this as: BMJ 2014;349:h1758

(c) BMJ Publishing Group Ltd 2015 